\title{
Community Acceptance Of The Covid-19 Vaccination Based On Health Behavior Theory (Health Belief Model And Theory Of Planned Behavior)
}

\author{
Fitrijaningsih \\ Faculty of Public Health, Muhammadiyah University of Jakarta \\ K.H. Ahmad Dahlan St, Cireundeu, Ciputat, South Jakarta, Banten 15419 \\ E-mail: fitrijarozak@gmail.com
}

\begin{abstract}
The availability and introduction of the COVID-19 vaccine as a new vaccine against SARS-CoV-2 are accompanied by challenges related to public acceptance from various circles. Vaccination is part of the main protective behavior against the COVID-19 pandemic. Identification of factors related to vaccine acceptance is needed to establish policies and formulate appropriate education for the community. This literature study was conducted by collecting data in the form of open access journals obtained from Google Scholar. The selection results determined that seven selected journals from abroad had compatibility between the topics and constructs in the Health Belief Model/HBM and Theory of Planned Behavior/TPB. More than $72 \%$ of respondents indicated their willingness to vaccinate against COVID-19. From the HBM point of view, individual perceptions of severity and susceptibility to COVID-19 have a positive correlation to vaccine acceptance along with perceived benefits. On the other hand, the negative correlation with vaccine acceptance arises due to public doubts regarding its side effects, efficacy, safety, and halalness. Subjective norm originating from policymakers has the most influential role on vaccine acceptance as a construct of PBT. HBM and $T P B$ can be used as a tool to find out the motivations and obstacles that affect people's attitudes towards the COVID-19 vaccine. The right strategy in increasing awareness and acceptance of the COVID-19 vaccine needs to be done to maintain trust and reduce public doubts about the COVID-19 vaccine so that vaccination coverage can be achieved maximally to achieve herd immunity.
\end{abstract}

Keywords: Covid-19 Vaccination, Health Behavior, Health Belief Model, Theory of Planned Behavior. 


\section{INTRODUCTION}

COVID-19 has become an international concern since its status was declared as a Public Health Emergency of International Concern (PHEIC) on January 30, 2020, by the World Health Organization (WHO) (1). Two months later, WHO declared the COVID-19 outbreak, which was first detected in Hubei Province, China, as a pandemic (2). The virus that appears and threatens the human population due to its very fast spread is the third type of coronavirus which is named SARS-CoV-2 or COVID-19 (Coronavirus disease) (3). Based on the WHO report as of May 25, 2021, more than 166 million people were confirmed positive with more than 3 million people dying worldwide (4). This virus is reported as a mutation of the SARS-CoV that spread in 2002 and MERS-CoV in 2012. Since the emergence of various viruses in the last 20 years such as the H1N1 virus, Ebola, Zika, SARS, MERS, until now COVID- 19, rapid vaccine development efforts are needed to reduce the number of transmissions worldwide (3). Vaccination is part of the main protective behavior against the COVID19 pandemic (5).

Historically, vaccines given in the form of mass immunization have proven successful in saving millions of lives and improving human health around the world, but in reality, there are still many conflicts in society from various environmental, cultural, political, and including psychological reasons (6). Not all people are willing to vaccinate because of doubts about the vaccine, causing delays in receiving or even refusing to vaccinate. This hesitation has been identified by WHO as one of the top ten global health threats that can affect vaccination coverage and may ultimately hinder success in controlling the COVID-19 pandemic (7), (8).

In various countries, safe and effective vaccines against COVID-19 are currently being developed, but how the acceptance and absorption of these vaccines by the public is still uncertain and presents unprecedented new challenges (5), (9). While new vaccines are still being developed, on the other hand, studies need to be conducted to obtain information about how they are accepted by the public and also to identify strategies to increase uptake rates once the vaccine is available and ready to use (5).

To get herd immunity against SARS-CoV-2 while stopping its transmission, it takes 55\%$82 \%$ vaccination coverage in a population. Identification of factors related to vaccine acceptance is needed to establish policies and formulate appropriate educational methods (10). An understanding is needed to find out the motivations and obstacles that affect people's intentions to receive the COVID19 vaccine (7). There is a lot of literature that discusses the acceptance of vaccines by the public and is supported by many theories of health behavior including the Health Belief Model (HBM) and the Theory of Planned Behavior (TPB). These theories describe several constructs associated with vaccination as well as during the implementation of H1N1 vaccination during the Influenza pandemic (11). 
Health belief theory (HBM) is an important tool that can be used to understand the factors that influence decision making by assessing what are the motivators and barriers for a person to adopt health behaviors (8). The theory, which was developed by social psychologists from the US Public Health Service in the 1950s, has become one of the most widely used models to examine the relationship between health behavior and the use of health services. The HBM suggests that individuals' involvement (or lack of involvement) in health promotion behaviors can be explained by their beliefs about health problems, perceived benefits and perceived barriers, self-efficacy, and cues to action that can trigger health-promoting behaviors (7), (8).

The theory of planned behavior (TPB) is another theoretical model proposed by Icek Ajzen that can be used to predict individual behavior in terms of intention to vaccinate. This theory explains several things that can affect a person's intention to vaccinate, namely attitudes toward vaccines (attitude toward a behavior), subjective norms for vaccination (subjective norms), and perceptions of behavioral control towards vaccination (perception of behavioral control) and self-efficacy (selfefficacy) which is an important predictor of health behavior (7).

This study aims to determine the factors that influence the acceptance of the COVID-19 vaccine referring to the Health Belief Model/ HBM and Theory Planned of Behavior / TPB. The results of this study are expected to provide information on what strategies can be applied to increase public understanding and acceptance of the COVID-19 vaccine based on the results obtained from the identification of constructs in the Health Belief Model/ HBM and Theory Planned of Behavior/ TPB.

\section{METHODS}

This literature study was conducted by collecting data in the form of open access journals obtained from Google Scholar using the keywords COVID-19, COVID-19 Vaccination, Health behavior, Health Belief Model and Theory Planned of Behavior. Based on these keywords, 52 journals were obtained. From the journals obtained, screening is then carried out by establishing journals that discuss individual attitudes or acceptance of COVID-19 vaccination based on the constructions contained in the HBM and TPB. The focus discussion in this study is on the constructions contained in the HBM theory, there are perceived vulnerability, perceived severity, perceived benefits, perceived barriers/ harm, and cues to action, and also the constructs contained in the TPB, there are attitudes toward behavior, subjective norm and perceived behavioral control. From this screening, seven (7) journals will be analyzed which are the results of research from various countries. 


\section{RESULTS AND DISCUSSIONS}

Table 1. Journal Literature

\begin{tabular}{|c|c|c|c|c|c|}
\hline Writer & Journal Title & $\begin{array}{l}\text { Health } \\
\text { Behavior } \\
\text { Theory }\end{array}$ & Country & $\begin{array}{l}\text { Number of } \\
\text { Respondents }\end{array}$ & $\begin{array}{c}\text { Willingness } \\
\text { to receive } \\
\text { COVID-19 } \\
\text { Vaccination }\end{array}$ \\
\hline $\begin{array}{l}\text { Martin C.S. Wong, Eliza } \\
\text { L.Y. Wong, Junjie } \\
\text { Huang, Annie W.L. } \\
\text { Cheung, Kevin Law, } \\
\text { Marc K.C. Chong, Rita } \\
\text { W.Y. Ng, Christopher } \\
\text { K.C. Lai, Siaw S. Boon, } \\
\text { Joseph T.F. Lau, Zigui } \\
\text { Chen, Paul K.S. Chan } \\
\text { (2021) }\end{array}$ & $\begin{array}{l}\text { Acceptance of the COVID- } \\
19 \text { vaccine based on the } \\
\text { health belief model: A } \\
\text { population-based survey in } \\
\text { Hong Kong (12) }\end{array}$ & HBM & Hong Kong & 1.200 & $\begin{array}{l}\text { Yes: } 42,2 \% \\
\text { No: } 57,8 \%\end{array}$ \\
\hline $\begin{array}{l}\text { Li Ping Wong, Haridah } \\
\text { Alias, Pooi-Fong Wong, } \\
\text { Hai Yen Lee \& Sazaly } \\
\text { AbuBakar (2020) }\end{array}$ & $\begin{array}{l}\text { The use of the health belief } \\
\text { model to assess predictors } \\
\text { of intent to receive the } \\
\text { COVID-19 vaccine and } \\
\text { willingness to pay (8) }\end{array}$ & HBM & Malaysia & 1159 & $\begin{array}{l}\text { Yes: } 94,3 \% \\
\text { No: } 5,7 \%\end{array}$ \\
\hline $\begin{array}{l}\text { Haoran Chu, Sixiao Liu } \\
(2021)\end{array}$ & $\begin{array}{l}\text { Integrating health behavior } \\
\text { theories to predict } \\
\text { American's intention to } \\
\text { receive a COVID-19 } \\
\text { vaccine (13) }\end{array}$ & HBM \& PBT & USA & 934 & $\begin{array}{l}\text { Yes: } 82,1 \% \\
\text { No: } 17,9 \%\end{array}$ \\
\hline Liora Shmueli (2021) & $\begin{array}{l}\text { Predicting intention to } \\
\text { receive COVID-19 vaccine } \\
\text { among the general } \\
\text { population using the health } \\
\text { belief model and the theory } \\
\text { of planned behavior model } \\
\text { (7) }\end{array}$ & HBM \& PBT & Israel & 398 & $\begin{array}{l}\text { Yes: } 80 \% \\
\text { No: } 20 \%\end{array}$ \\
\hline $\begin{array}{l}\text { Mohammad } \\
\text { Hossain, Md. Zakiul } \\
\text { Alam, Md. Syful Islam, } \\
\text { Shafayat Sultan, Md. } \\
\text { Mahir Faysal, Sharmin } \\
\text { Rima, Md. Anwer } \\
\text { Hossain, Abdullah Al } \\
\text { Mamun (2021) }\end{array}$ & $\begin{array}{l}\text { Health Belief, Planned } \\
\text { Behavior, or Psychological } \\
\text { Antecedents: What predicts } \\
\text { COVID-19 Vaccine } \\
\text { Hesitancy better among the } \\
\text { Bangladesh Adults? (6) }\end{array}$ & HBM \& PBT & Bangladesh & 1497 & $\begin{array}{l}\text { Yes: } 60,6 \% \\
\text { Doubt: } \\
39,4 \%\end{array}$ \\
\hline $\begin{array}{l}\text { Paul L. Reiter, Michael } \\
\text { L. Pennell, Mira L. Katz } \\
(2020)\end{array}$ & $\begin{array}{l}\text { Acceptability of a COVID- } \\
19 \text { vaccine among adults in } \\
\text { the United States: How } \\
\text { many people would get } \\
\text { vaccinated? (5) }\end{array}$ & HBM & USA & 2006 & $\begin{array}{lr}\text { Yes: } & 69 \% \\
(48 \% & \text { Sure, } \\
21 \% & \\
\text { Maybe) } & \\
\text { No: } & 31 \% \\
(17 \% & \text { Not } \\
\text { sure, } & 5 \% \\
\text { Maybe } & \text { no, } \\
9 \% & \\
\text { Definitely } \\
\text { no) } & \\
\end{array}$ \\
\hline $\begin{array}{l}\text { Ke Chun Zhang, Yuan } \\
\text { Fang, He Cao, Hongbiao }\end{array}$ & $\begin{array}{l}\text { Parental Acceptability of } \\
\text { COVID-19 Vaccination for }\end{array}$ & PBT & China & 1052 & $\begin{array}{l}\text { Yes: } 76,4 \% \\
\text { No: } 23,6 \%\end{array}$ \\
\hline
\end{tabular}




\begin{tabular}{|c|c|c|c|c|c|}
\hline Writer & Journal Title & $\begin{array}{l}\text { Health } \\
\text { Behavior } \\
\text { Theory }\end{array}$ & Country & $\begin{array}{l}\text { Number of } \\
\text { Respondents }\end{array}$ & $\begin{array}{c}\text { Willingness } \\
\text { to receive } \\
\text { COVID-19 } \\
\text { Vaccination }\end{array}$ \\
\hline $\begin{array}{l}\text { Chen, Tian Hu, Ya Qi } \\
\text { Chen, Xiaofeng Zhou, } \\
\text { Zixin Wang }(2020)\end{array}$ & $\begin{array}{l}\text { Children Under the Age of } \\
18 \text { Years: Cross-Sectional } \\
\text { Online Survey (14) }\end{array}$ & & & & \\
\hline
\end{tabular}

The Health Belief Model (HBM) has been one of the most widely used conceptual frameworks in health behavior research since the early 1950s (15), (16). This framework is used either to describe the change or maintenance of behavior related to health behaviors, or as a guide in conducting health behavior interventions. Over the past two decades, HBM has evolved and is used to support interventions to change health behaviors. The components in the Health Belief Model (HBM) are perceived severity, perceived vulnerability, potential harm, perceived barriers, perceived benefits, cues to action (cue/ intention to act), and self-efficacy. This last component was added as a separate construct as suggested by Rosenstock, Strecher, and Becker in 1988 (15).

Perceived vulnerability refers to respondents' beliefs about their vulnerability to contracting COVID-19. Perceived susceptibility affects intention to vaccinate. Wong Li reported that participants who have perceived susceptibility to contracting COVID-19 had a more definite intention to vaccinate $(\mathrm{OR}=1.36,95 \%$ CI 1.04-1.79) (8). Participants' willingness to vaccinate also tends to be owned by correspondents with a high perception of susceptibility as shown by Reiter's study ( $R R=1.05,95 \%$ CI: 1.01-1.09) (5). Shmueli in his research in Israel also revealed that groups who feel more susceptible to disease, also feel a greater risk of infection or experience higher complications so that this makes them intend to vaccinate (7). Another thing related to susceptibility was reported in a study with a different concept conducted by Hossain who said that increased perceptions of susceptibility to COVID-19 are tended to reduce hesitation to vaccinate $(\beta=-0.06, p<0.05)(6)$. The low perception of vulnerability was reported by Chu who conducted his research in the USA. From this study, it was found that although most respondents knew the severity of COVID-19, they tended to underestimate the risk of contracting this disease. The relationship of perceived susceptibility to vaccination intention was close to statistical significance $(B=0.114, \mathrm{SE}=0.062, \mathrm{p}=0.064)(13)$. Different from the other five journals, Wong Martin provided a different finding in his research, that there was no relationship between perceived susceptibility to vaccine reception $(\mathrm{aOR}=10.2,95 \%$ CI 0.83 to 1.17 , $\mathrm{p}<0.839$ ). This condition can be explained because of the public's view that COVID-19 is a mild disease, except for people who are indeed at risk (12).

Most of the results from this study indicate a positive relationship between perceived susceptibility and acceptance of the COVID-19 vaccine. Respondents who have a serious perception of susceptibility to COVID-19 are more likely to choose to accept the offered COVID-19 vaccination. However, appropriate promotion and education strategies must be considered to prevent transmission 
and increase acceptance of COVID-19 vaccination, especially for people who have a low perception of susceptibility to SARS-CoV-2.

Perceived severity refers to the severity felt when exposed to COVID-19. In general, study participants viewed COVID-19 as a serious disease (Chu, Shmueli, Reiter, Wong Li). As research conducted by Wong Martin in Malaysia found, especially in respondents who considered COVID-19 a serious problem, they would be more receptive or willing to vaccinate [aOR] $1.1695 \%$ C.I. 1.01 to $1.32, p=0.037$ (12). This is in line with the study conducted by Shmueli which stated that perceived severity was one of the most significant predictors of intention to receive COVID-19 vaccination (OR $=2.36$, 95\% CI 1.58-3.51) (7). Hossain found that increasing COVID-19 severity also reduced the level of doubt about the COVID-19 vaccine $(\beta=-0.11, p<0.01)(6)$. In America, study respondents were more likely to be willing to get vaccinated than those who had the perception that COVID-19 was a serious disease $(\mathrm{RR}=1.08,95 \% \mathrm{CI}: 1.04-1.11)(5)$.

Most of the results from this study indicate a positive relationship between perceived severity and acceptance of the COVID-19 vaccine. Respondents who have a serious perception of the severity of COVID-19 are more likely to choose to accept the vaccinations offered. The COVID-19 Vaccine promotion strategy by emphasizing the severity of COVID-19 can help to raise awareness of people with low perceptions of vulnerability.

Perceived benefits refer to the benefits that will be felt or obtained if participants follow the government's recommendation to vaccinate against COVID-19. Most of the participants had a high perception of the benefits of the COVID-19 vaccine, namely the belief that vaccination reduces the likelihood of COVID-19 infection (OR $=2.51,95 \%$ CI 1.19-5.26) (8). People's perceived benefits and positive attitudes towards the COVID-19 vaccine influenced the intention to vaccinate as reported by the Chu with an estimated total effect $(0.376$ CI $95 \%=0.180-0.572)(13)$. Participants were more likely to vaccinate if there was a higher rate of benefit from the COVID-19 vaccine (OR $=4.49,95 \%$ CI 2.79-7.22) (7). The research on doubts about vaccination was carried out by Hossain in Bangladesh. This study reported that the perceived benefit of vaccination would reduce respondents' doubts about the vaccine and increase the intention to vaccinate $(\beta=-0.33, p<0.01)(6)$. According to Reiter, a high perceived benefit of vaccines also increases the desire to vaccinate against COVID-19 $(\mathrm{RR}=1.46,95 \%$ CI: $1.40-1.52)(5)$.

Most of the results from this study indicate a positive relationship between perceived benefits and acceptance of the COVID-19 vaccine. Respondents who have a positive view of the benefits of the COVID-19 vaccine are more likely to choose to accept the offered vaccination.

Perceived barriers refer to the perceived barriers or negative impacts associated with COVID19 vaccination. Most of the components in the HBM have a significant relationship with vaccine acceptance, especially in respondents who consider COVID-19 as a serious problem and in respondents who see the benefits of vaccination. On the other hand, perceived barriers and perceived 
harm to the offered vaccine will have a negative relationship to vaccine acceptance, as reported in a study conducted by Wong Martin which showed a negative correlation between perceived inhibition $(\mathrm{OR} 0.80,95 \%$ CI $0.68-0.94, \mathrm{p}=0.007)$ and perceived hazard $(\mathrm{aOR} 0.77,95 \%$ CI $0.64-0.94, \mathrm{p}=$ 0.008) to vaccine reception (12). Based on research conducted by Hossain, perceived barriers also tend to increase hesitancy to get the COVID-19 vaccine $(\beta=0.30, p<0.01)(6)$. Various perceived barriers were found in the research conducted by Wong Li in Malaysia. These barriers are related to the introduction of new vaccines, side effects, efficacy, safety, and halalness of vaccines. Muslims rejecting immunization because vaccines are not halal (i.e., not permissible under Islam) has become a major problem in Malaysia and many Muslim countries around the world. In this study, the low level of vaccine hazard affected the intention to vaccinate ( $\mathrm{OR}=2.19,95 \%$ CI $1.03-4.65)$. Vaccine safety is getting more attention than the total cost (8). Safety issues have a greater influence on the intention to vaccinate (13). Study participants were less likely to want to get vaccinated if they found a higher level of vaccine hazard ( $R R=0.95,95 \%$ CI: 0.92-0.98) (5).

Most of the results from this study indicate a negative relationship between perceived barriers/ hazards and acceptance of the COVID-19 vaccine. Respondents who have a perception of serious obstacles/ dangers to the COVID-19 vaccine tend to refuse the vaccination offered. Promotional strategies that emphasize the importance of vaccination and guarantees related to the effectiveness and safety of COVID-19 vaccines are very important in increasing vaccination coverage rates in the community. Meanwhile, in countries with Muslim populations, the halalness of vaccines is also a major consideration for receiving the offered vaccines, so the government, the ministry of health, health workers, and including religious leaders need to work together to accommodate this obstacle. The amount of public attention to this new vaccine must get attention from the government to maintain trust and reduce public doubts about the COVID-19 vaccine (17).

Cues to action refer to cues that trigger readiness and willingness to vaccinate against COVID-19. The cue to action is an important element of the HBM that played a significant role in the acceptance of the COVID-19 vaccine (aOR 2.61, 95\% C.I. 2.32 to 2.94, p < 0.001). Recommendations from the government are the most important and most instrumental cues compared to others, for example from doctors or family members $(\mathrm{aOR}=10.2,95 \%$ C.I. 6.54 to $15.9, \mathrm{p}<$ 0.001). Thus, the research conducted by Wong Martin shows the need for the government's role to increase public attention to participate in vaccination (12). The results of research conducted by Shmueli also showed results that were almost the same as those found by Wong Martin. In Israel, recommendations from the Ministry of Health and general practitioners, or the availability of vaccinations in the workplace were the biggest predictors of intention to get COVID-19 vaccination $(\mathrm{OR}=1.99,95 \%$ CI 1.38-2.87) (7). The provision of comprehensive information related to COVID19 also plays a role in receiving vaccinations (8). Different findings were reported in a study conducted by Hossain in Bangladesh. In this study, the cue construct for action includes implicit or 
explicit stimuli or situations that can motivate to vaccinate such as information from the mass media does not have a significant effect on the intention to vaccinate except for respondents who get information about the COVID-19 vaccine through social media. (eg Facebook) or online news portals. The information obtained from these sources was able to reduce their doubts about the COVID-19 vaccine $(\beta=-0.05, \mathrm{p}<0.05)(6)$.

Most of the results from this study indicate a positive relationship between cues to action and acceptance of the COVID-19 vaccine. The role of the government, ministry of health, general practitioners, and social media can be important predictors to increase public interest in receiving COVID-19 vaccinations. World Health Organization (WHO) also gave reasons for the important role of social media as a means of communication to the wider community. The first reason is that social media helps to communicate regularly and provide the latest information promptly to the people. The second reason is that currently, social media has also become a means of communication for most people around the world. The last reason is that social media is also one of the places for anti-vaccine activists to spread negative messages about vaccines. These negative messages include rumors, distorting facts, giving false or misleading opinions or information, and so on. Responding to this negative message positively, empathizing with people's concerns, and providing/ correcting misinformation are recommendations from WHO to be implemented in providing socialization related to the COVID-19 vaccine (18).

Planned Behavior Theory by Ajzen (1991) is a development of The Theory of Reasoned Action proposed by Ajzen and Fishbein (1980). The Theory of Reasoned Action assumes that a person's behavior is determined through the individual's desire to perform or not to perform a certain behavior or vice versa (19). This behavior is driven by intentions that are influenced by behavioral beliefs and normative beliefs (20). This theory was then refined by Ajzen (1988) by adding one factor, namely perceived behavior control. With this factor, Reasoned Action Theory turns into Planned behavior theory (21). Conceptually, in the Planned behavior theory, three determinants that influence intentions, there is attitude toward behavior, subjective norm, and perceived behavior control (22).

Attitude toward behavior refers to how a person assesses, responds to, or believes that the COVID-19 vaccine is effective in protecting themselves from the transmission of COVID-19. In research conducted by the Chu showed that Americans generally have a positive view of the COVID19 vaccine. Positive attitudes towards vaccines and recent vaccination history have a positive correlation with the intention to vaccinate against COVID-19 (13). A positive attitude towards COVID-19 vaccination was also associated with parental acceptance of vaccination against their children [AOR] 1.70, 95\% CI 1.50-1.91) (14). Meanwhile, respondents who have a negative response to the COVID-19 vaccine will show doubts about receiving the COVID-19 vaccination $(\beta=0.27$, $\mathrm{p}<0.01)(6)$. 
Most of the results from this study indicate a positive relationship between the attitudes or views of respondents about the COVID-19 vaccine and their willingness to receive vaccinations. The public's positive attitude towards the COVID-19 vaccine will greatly contribute to increasing vaccination coverage to suppress the spread of SARS-CoV-2.

Subjective norm refers to the social pressure felt when wanting to do or not wanting to get a COVID-19 vaccination. The Chu categorizes these subjective norms into two groups, there are command norms derived from policymakers and descriptive norms which indicate important behaviors of others. Regarding the COVID-19 vaccine, it is likely that subjective norms affect selfefficacy, which in turn will affect the intention to receive vaccination (13). The high perception of subjective norms was also positively correlated to vaccinate against COVID-19 in Israel (OR = 3.04, 95\% CI 2.15-4.30) as in a study conducted by Shmueli (7). Doubts about COVID-19 vaccination tended to decrease as family support increased in Bangladesh $(\beta=-0.31, p<0.01)(6)$. Family support in this case parents is also a predictor for parents to vaccinate their children with COVID-19 in China (AOR 4.18, 95\% CI 3.21-5.43) (14).

Most of the results of this study indicate a positive relationship between subjective norms and willingness to receive vaccinations. Government support as a policymaker and support from families can reduce doubts about receiving vaccinations.

Perceived behavior control refers to the perceived ease or difficulty in following the government's recommendation to vaccinate against COVID-19. A study conducted by Zhang showed that perceived behavioral control by parents regarding COVID-19 vaccination would be associated with higher parental acceptance of allowing their children to be vaccinated (AOR 1.84, 95\% CI 1.492.26). Positive information from social media about the COVID-19 vaccine also increased the attention of parents to vaccinate their children (AOR 1.35, 95\% CI 1.17-1.56). On the other hand, negative information from social media regarding COVID-19 vaccination will reduce parents' attention to vaccinate their children (AOR 0.85 , 95\% CI 0.74-0.99) (14). Indecision in vaccinating against COVID-19 is related to perceptions of behavioral control as reported by Hossain. In this journal, it was stated that respondents who consciously registered for the COVID-19 vaccination had a lower level of doubt $(\beta=-0.05, p<0.05)$. To anticipate increasing doubts or the emergence of regret, the respondents were anticipating so that the level of doubt about the COVID-19 vaccine was less than before $(\beta=-0.18, \mathrm{p}<0.01)(6)$.

Most of the results of this study indicate a positive relationship between perceived behavioral control and willingness to receive vaccinations. Positive information related to the COVID-19 vaccine plays an important role in reducing public doubts about the vaccination that will be received. 


\section{CONCLUSIONS AND SUGGESTIONS}

The availability and introduction of the COVID-19 vaccine as a new vaccine against SARS$\mathrm{CoV}-2$ were accompanied by challenges related to public acceptance from various circles. The results of research conducted in several countries show that more than $72 \%$ of respondents indicated their willingness to vaccinate against COVID-19. From the perspective of the Health Belief Model (HBM), vaccine acceptance is largely influenced by individual perceptions of the severity and susceptibility to COVID-19. These two perceptions have a positive correlation to vaccine acceptance along with perceived benefits. On the other hand, the COVID-19 vaccine has also raised doubts in the community regarding its side effects, efficacy, safety, and halalness. The perception of this barrier has a negative correlation with the individual's willingness to receive the COVID-19 vaccine. Subjective norm has the most influential role on vaccine acceptance as a construct of the Theory Planned of Behavior (TPB). Norm orders from policymakers have an effect on self-efficacy which in turn will affect the intention to receive the COVID-19 vaccination.

These findings need to be considered by policymakers and health care providers as a discourse in determining strategies to increase public acceptance of vaccination. Among the things that can be done are:

a. Increase public knowledge and awareness of SARS-CoV-2 which can be done through socialization either directly or indirectly through various media including social media.

b. Transparency concerning the vaccine development process and socialization regarding the safety, effectiveness, benefits, and halalness of vaccines to increase public trust.

c. Cooperation is needed between the government, the ministry of health, health workers, and including religious leaders to maintain trust and reduce public doubts about the COVID-19 vaccine.

\section{REFERENCES}

1. Catrin Sohrabi, Alsafi Z, O’Neill N, Khan M, Kerwan A, Al-Jabir A, et al. World Health Organization declares global emergency: A review of the 2019 novel coronavirus (COVID-19). Diabetes Metab Syndr. 2020;14(4)(January):337-9.

2. ILO. Dalam menghadapi pandemi: Memastikan Keselamatan dan Kesehatan di Tempat Kerja [Internet]. Labour Administration, Labour Inspection and Occupational Safety and Health Branch (LABADMIN/OSH) Route. Geneva, Switzerland; 2020. 1-52 p. Available from: https://www.ilo.org/wcmsp5/groups/public/---asia/---ro-bangkok/---ilojakarta/documents/publication/wcms_742959.pdf

3. Syamaidzar S. Review Vaksin Covid-19. Res Gate. 2020;(July):1-15.

4. WHO. Coronavirus disease (COVID-19) [Internet]. 2021 [cited 2021 May 25]. Available from: https://www.who.int/emergencies/diseases/novel-coronavirus-2019 
5. Reiter PL, Pennell ML, Katz ML. Acceptability of a COVID-19 vaccine among adults in the United States: How many people would get vaccinated? Vaccine. 2020;38(January):6500-7.

6. Hossain MB, Alam Z, Islam S, Sultan S, Faysal M, Rima S, et al. Health Belief, Planned Behavior, or Psychological Antecedents: What predicts COVID-19 Vaccine Hesitancy better among the Bangladeshi Adults? 2021;

7. Shmueli L. Predicting intention to receive COVID-19 vaccine among the general population using the Health belief model and the theory of planned behavior model. medRxiv. 2020;1-13.

8. Wong LP, Alias H, Wong PF, Lee HY, AbuBakar S. The use of the health belief model to assess predictors of intent to receive the COVID-19 vaccine and willingness to pay. Hum Vaccines Immunother [Internet]. 2020;16(9):2204-14. Available from: https://doi.org/10.1080/21645515.2020.1790279

9. World Health Organization (WHO). Behavioural considerations for acceptance and uptake of COVID-19 vaccines. World Health Organization (WHO). 2020. 18 p.

10. Sanche S, Ling YT, Xu C, Romero-Severson E, Hengartner N, Ruian Ke. Research High Contagiousness and Rapid Spread of Severe Acute Respiratory Syndrome Coronavirus 2. Emerg Infect Dis. 2020;26(7):1470-7.

11. Sherman SM, Smith LE, Sim J, Amlôt R, Cutts M, Dasch H, et al. COVID-19 vaccination intention in the UK: results from the COVID-19 vaccination acceptability study (CoVAccS), a nationally representative cross-sectional survey. Hum Vaccines Immunother [Internet]. 2020;00(00):1-10. Available from: https://doi.org/10.1080/21645515.2020.1846397

12. Wong MCS, Wong ELY, Huang J, Cheung AWL, Law K, Chong MKC, et al. Acceptance of the COVID-19 vaccine based on the health belief model: A population-based survey in Hong Kong. $\begin{array}{llll}\text { Vaccine } \quad \text { 2021;39(7):1148-56. Available from: } & \text { f }\end{array}$ https://doi.org/10.1016/j.vaccine.2020.12.083

13. Chu H, Liu S. Integrating health behavior theories to predict American's intention to receive a COVID-19 vaccine. Patient Educ Couns [Internet]. 2021;(xxxx). Available from: https://doi.org/10.1016/j.pec.2021.02.031

14. Zhang KC, Fang Y, Cao H, Chen H, Hu T, Chen YQ, et al. Parental acceptability of COVID-19 vaccination for children under the age of 18 years: Cross-sectional online survey. JMIR Pediatr Parent. 2020;3(2):1-13.

15. Glanz K, Rimer BK, Viswanath K. Health education and health behavior. 4th ed. Health Education \& Behavior. 2008.

16. Conner M, Norman P. Predicting Health Behaviour: reseaarch and practice with social congnition model. 2nd ed. Conner M, Norman P, editors. Predicting Health Behaviour. UK: Open University Press McGraw-Hill Education; 2006.

17. World Health Organisation. COVID-19 Vaccines: Safety Surveillance Manual Module: 
Establishing surveillance systems in countries using COVID-19 vaccines. 2020.

18. World Health Organization (WHO). COVID-19 vaccine safety communication. 2020. 1-18 p.

19. Mahyarni. Theory Of Reasoned Action Dan Theory Of Planned Behavior (Sebuah Kajian Historis tentang Perilaku). J El-Riyasah [Internet]. 2013;4(1):13-23. Available from: http://ejournal.uin-suska.ac.id/index.php/elriyasah/article/view/17/13

20. Riyadi, Larasaty P. Factors Affecting Community Compliance With Health Protocols In Preventing The Spread Of Covid-19). Semin Nas Off Stat 2020 Pemodelan Stat tentang Covid19. $2020 ; 19: 45-54$.

21. Seni NNA, Ratnadi NMD. Theory of Planned Behavior Untuk Memprediksi Niat Berinvestasi. E-Jurnal Ekon dan Bisnis Univ Udayana. 2017;12:4043.

22. Icek A. The Theory of Planned Behavior. In: Organizational Behavior and Human Decision Processes. 1991. p. 179-211. 